\title{
Controlled Preparation and Surface Structure Characterization of Carbon-Coated Lithium Iron Phosphate and Electrochemical Studies as Cathode Materials for Lithium Ion Battery
}

\author{
Xiangcheng Sun ${ }^{1, *}$, Kai Sun ${ }^{2}$, Caiyun Chen $^{3}$, Haiping Sun ${ }^{2}$, Bo Cui ${ }^{1}$ \\ ${ }^{1}$ Department of Electrical and Computer Engineering, University of Waterloo, Waterloo, Canada \\ ${ }^{2}$ Department of Materials Science and Engineering, University of Michigan, Ann Arbor, Michigan 48109 US \\ ${ }^{3}$ Department of Materials Science and Engineering, Shandong University of Technology, Zibo, PR China
}

\begin{abstract}
Amorphous carbon-coated lithium iron phosphate $\left(\mathrm{C}-\mathrm{LiFe}_{4}\right)$ particles have been mass synthesized at the commercial scale by a controlled solid-state reaction method. Particles morphologies, olivine-type phase structures and the carbon coating features were investigated in details by various techniques as X-ray diffraction analysis (XRD), scanning electron microscopy (SEM) imaging, and transmission electron microscopy (TEM, HRTEM) imag ing, selected-area electron diffraction (SAED), X-ray energy dispersive spectroscopy microanalysis (XEDS), and X-ray photoelectron spectroscopy (XPS). Single-crystal nature of the olivine type $\mathrm{LiFePO}_{4}$ structures was revealed by XRD and SAED analyses. TEM imaging showed rough nanoparticles spherical features with average size range of 50-200 $\mathrm{nm}$. Homogenous coating features of carbon layers on the particles surface and olivine- $\mathrm{LiFePO}_{4}$ phase are clearly observed in HR-TEM imaging and confirmed by the corresponding SAED pattern. Elementalb inding energy from XPS analysis also confirmed that an amo rphous sp2 carbon coating layer and olivine type $\mathrm{LiFePO}_{4}$ structures. It is indicated that the characteristics of sp2 type conducting-coating layer on the particles surfaces gave rise to improved electrical conductivity by reducing the diffusion path of the electron and lithium ions, as directly evidenced from our charge-discharge cycling testing as the cathode in the Lithium ion battery cell.
\end{abstract}

Keywords Lithium Iron Phosphate, Olivine-Type Phase, X-Ray Diffraction, Transmission Electron Microscopy, X-Ray Photoelectron Spectroscopy, Electrochemical Capacity

\section{Introduction}

Extensive attention has been devoted to the development and characterizations of the phospho-olivine type lithium iron phosphate $\left(\mathrm{LiFePO}_{4}\right)$ as an attractive cathode candidate in the lithium ion battery market, which was first reported by John Goodenough in 1997 as a promising cathode electrode for the rechargeable lithium-ion batteries[1]. Olivine-type $\mathrm{LiFePO}_{4}$ exhibits various unique advantages such as low toxicity, low cost, high thermal and chemical stability, and good electrochemical performance in the fully charged state, and it also has a higher theoretical specific capacity (170 $\mathrm{mAh} \mathrm{g}^{-1}$ ) and a flat charge-discharge profile at intermediate voltage (3.45 $\mathrm{V}$ vs $\left.\mathrm{Li}^{-} \mathrm{Li}^{+}\right)$, and reasonable cycle life[2-3]. However, $\mathrm{LiFePO}_{4}$ has inherently low electrical conductivity, which results in its poor rate capability due to the poor

* Corresponding author:

sunxc824@gmail.com (Xiangcheng Sun)

Published online at http://journal.sapub.org/ijmc

Copyright (C) 2012 Scientific \& Academic Publishing. All Rights Reserved kinetics of lithium intercalation/deintercalation process [2-15]. Th is causes a bigger challenge for power-demanding applications such as hybrid electric vehicles and electric vehicles[2-6]. Nowadays many approaches have been successfully adopted to improve its electrical conductivity, such as metal cation doping and carbon-coating or addition[7-12], decreasing the particle size and producing nanoparticles [13-18]. It has been reported that carboncoating would increase the surface electrical conductivity and smaller size of $\mathrm{LiFePO}_{4}$ could shorten the diffusion length of Li-ion during lith iumintercalation/deinte rcalation process[3, 6, 20]. Particularly, it is apparent that carbon coating has been reported to be very effective in the enhancement of capacity and rate capability on $\mathrm{LiFePO}_{4}$ cathode[6-20, 24-33].

In the present work, we report large-scale commercial synthesis and structural morphologies of carbon coated lithium iron phosphate $(\mathrm{C}-\mathrm{LiFePO}$ ) partic les prepared using home-made amorphous micro- $\mathrm{FePO}_{4}$ as the iron source and conducting black as carbon source. Furthermore, we examined the electrochemical performance of the 
C-LiFePO 4 particles as a cathode for the lithium-ion battery.

\section{Experiments}

\subsection{Sample Preparation}

First of all, in order to produce the homogenous carbon-coated $\mathrm{LiFePO}_{4}$ products, the choice of suitable chemical precursors and starting reagents is very essential. Meanwhile, the appropriate temperature and pressure must be carefully selected to prevent the undesirable particle growth and the presence of impurity phase. Otherwise, undesired impurities, such as $\mathrm{Fe}_{2} \mathrm{O}_{3}$ and $\mathrm{Fe}_{2} \mathrm{P}$, can be contained in the final products.

Here, micro- $\mathrm{FePO}_{4}$ powders were firstly synthesized via the solid-state reaction (i.e. pre-calcination), which was typically conducted by heating the mixture of the relatively cheap precursors of $\mathrm{FeSO}_{4}$ and $\mathrm{NH}_{4} \mathrm{H}_{2} \mathrm{PO}_{4}$ (e.g. $\left.\mathrm{FeSO}_{4}: \mathrm{NH}_{4} \mathrm{H}_{2} \mathrm{PO}_{4}=1: 2\right)$ at up to $300^{\circ} \mathrm{C}$. Consequently, the appropriate stoichiometric amount (e.g. 2:1) of amorphous micro-FePO $\mathrm{O}_{4}$ powders and $\mathrm{Li}_{2} \mathrm{CO}_{3}$ powders were deeply calcinated under the high-temperature carbonization with presence of the conductive carbon source (i.e. acetylene black) in an industrial-type furnace. All the reagents used in the experiment are of analytical purity.

Usually, the high temperature solid state calcination was systemically carried out under controlled temperature ranges $\left(700^{\circ} \mathrm{C}-800^{\circ} \mathrm{C}\right)$ and certain pressure for over $5-10 \mathrm{~h}$. By controlling the calcination temperature and atmosphere pressures, the $\mathrm{LiFe}_{4} \mathrm{PO}_{4}$ powders products could be produced maximum at $5 \mathrm{~kg} / \mathrm{day}$. The yield purity of the as-prepared $\mathrm{LiFePO}_{4}$ powders was up to $95 \%$ that collected in the bag filter regardless of the conducting carbon sources.

\subsection{Sample Characterization}

The phase purity and microstructure were characterized and recorded by XRD using a $\mathrm{D} / \max ^{-2000}$ Rigaku diffractometry with $\mathrm{Cu} \mathrm{K \alpha}$ radiation $(\lambda=0.15406 \mathrm{~nm})$

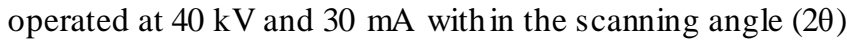
ranging from $20^{\circ}$ to $70^{\circ}$, and a step of $0.01^{\circ}$.

The mo rphologies of as-prepared particles were examined using a scanning electron microscopy (Carl Zeiss, InLens, $\mathrm{WD}=9.6,15 \mathrm{Kv}$ ). The dispersed particles supported on a 200 mesh holy carbon film coated Cu grids were characterized at nanoscale by a conventional transmission electron microscopy (TEM) and high-resolution transmission electron microscopy (HR-TEM), and selected area electron diffraction (SAED) techniques using a JEOL 3010 microscopy equipped with XEDX systemat $300 \mathrm{kV}$. Surface chemical elements characterizations of particles were determined and recorded by X-ray photoelectron spectrometer (XPS) using a Kratos ULTRA DLD XPS with a mono-chromated $\mathrm{Al}$ source that gives an energy resolution better than $0.5 \mathrm{eV}$ at a pass energy smaller than $20 \mathrm{eV}$. Both survey scans (with a pass energy of $160 \mathrm{eV}$ and a scan step of $1 \mathrm{eV}$ ) and core scans (with a pass energy of $20 \mathrm{eV}$ and a scan step of $0.1 \mathrm{eV}$ ) were collected. The spectra were calibrated by setting the $\mathrm{C} 1 \mathrm{~s}$ peak as $285 \mathrm{eV}$.

Electrochemical properties were measured on electrodes prepared by using the mixtures of comprising $85 \mathrm{wt} \%$ active materials, $10 \mathrm{wt} \%$ acetylene black, and $5 \mathrm{wt} \%$ polyvinylidene fluorides (PVDF) binder. The $\mathrm{LiFePO}_{4}$ electrode films were fabricated by doctor blade technique on aluminum foil. The cells consisted of the electrode, a lithium metal counter electrode and the electrolyte of a $1 \mathrm{M}$ solution of $\mathrm{LiPF}_{6}$ in ethylene carbonate/dimethyl carbonate (EC/DMC, 1:1). The cells were assembled and handled in an Ar-filled glove box and were evaluated using coin-type cells. Galvanostatic discharge/charge tests were carried out using a program-controlled LAND Celltest-2001A system between $2.5 \mathrm{~V}$ and $4.2 \mathrm{~V}$ versus the Lithium counter electrode at room temperature.

\section{Results and Discussion}

The powder $\mathbf{X}$-ray diffraction pattern (XRD) taken from the as-prepared particles is shown in Fig.1. It clearly revealed that the C-LiFePO ${ }_{4}$ particles were indexed well to a pure orthorhombic system of olivine-type structure $\left(\mathrm{P}_{\mathrm{nm}}\right.$, JCPDS: 40-1499). No any impurities phase such as transition metal co mpounds $\mathrm{Li}_{3} \mathrm{PO}_{4}$ and $\mathrm{FePO}_{4}$ were detected by XRD. Carbon phase was not found apparently from the XRD pattern, which indicates it may exist in amorphous form.

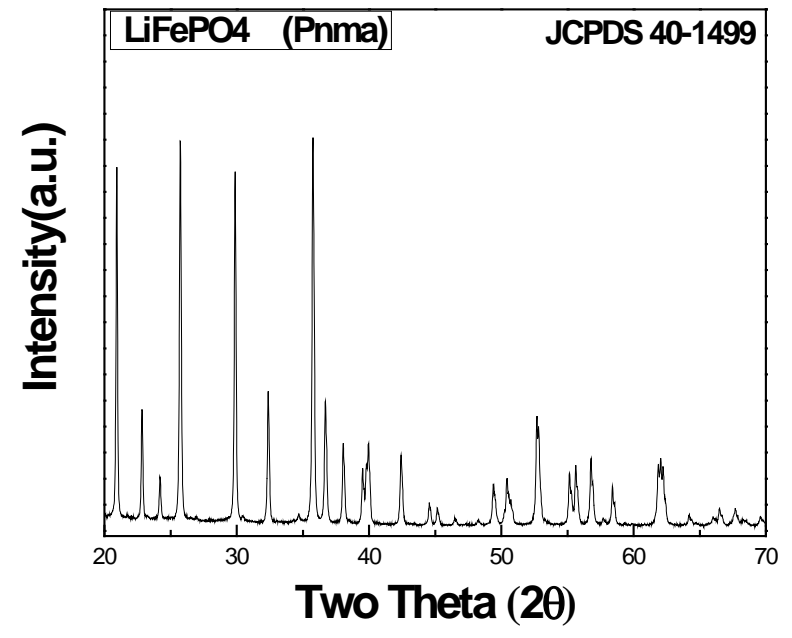

Powder XRD pattern of the $\mathrm{C}-\mathrm{LiFePO}{ }_{4}$ particles

Figure 1. Powder XRD pattern

From the SEM images shown in Fig.2a and Fig.2b, it is observed that the as-prepared $\mathrm{LiFePO}_{4}$ particle assemblies exhibiting spherical or elliptical morphology with nano-aggregated surface features having a size distribution from 1-3 $\mu \mathrm{m}$. The typical bright-field magnified TEM images in Fig.3a shows that the $\mathrm{LiFePO}_{4}$ particles assemblies are composed of densely aggregated nanoparticles showing rough spherical shapes with sizes in the range of 50-200 $\mathrm{nm}$ regardless of the types of carbon sources used. Further details are evidenced from the selected area electron diffraction (SAED) pattern showed in the Fig. 3b. The appearance of distinct and diffuse SAED rings 
confirms the co-existence of an amorphous phase together with $\mathrm{LiFePO}_{4}$ crystal phase. Fig. $3 \mathrm{c}$ is a HR-TEM image that gives further insight of the morphology of $\mathrm{C}-\mathrm{LiFePO}_{4}$ particle, such a HR-TEM image view clearly indicated that an amorphous carbon layer overed the surface of the $\mathrm{LiFePO}_{4}$ particles with a thickness of 3-4 nm layer, and its corresponding SAED pattern shown in Fig.3d can be indexed as the[100] direction of the olivine phase crystal. It has been reported that the formation of amorphous carbon in the surfaces of the particles owes to the nature of the carbon source during solid-reactions, and was indeed generated by carbonization of the conductive carbon source precursor[19, 20]. Meanwhile, it is observed that the coating layer was uniform and the thickness of carbon on the partic le was in the range of several nanometers, suggesting that the carbon precursor played an important role in reducing the $\mathrm{LiFePO}_{4}$ particle size during the high temperature calcinations process. This result is obviously attributable to the amorphous carbon coating that inhibits grain growth as reported by several groups[19-21]. The well-resolved lattice fringes demonstrate the high crystalline and single-crystal features of the core-LiFePO ${ }_{4}$ structures. The d-spacing of $0.47 \mathrm{~nm}$ as marked in Fig.3c is consistent with spacing of the (001) plane of the orthorhombic $\mathrm{LiFePO}_{4}$ phase. The corresponding SEAD pattern also clearly confirms the single-crystal and olivine-phase nature of the $\mathrm{LiFePO}_{4}$ particle. The index of the electron diffraction spots corresponding to the (020) and (002) planes of $\mathrm{LiFePO}_{4}$ crystals are labelled in Fig.3d, further revealing the single-crystalline nature of the $\mathrm{LiFePO}_{4}$ particles during solid state reaction under higher temperature and pressures.

The corresponding selected area XEDS spectrum collected from the particles shown in Fig.3a is given in Fig.4. It shows that the as-prepared particles consist of all the elements of the crystal phase and the amo rphous carbon element.
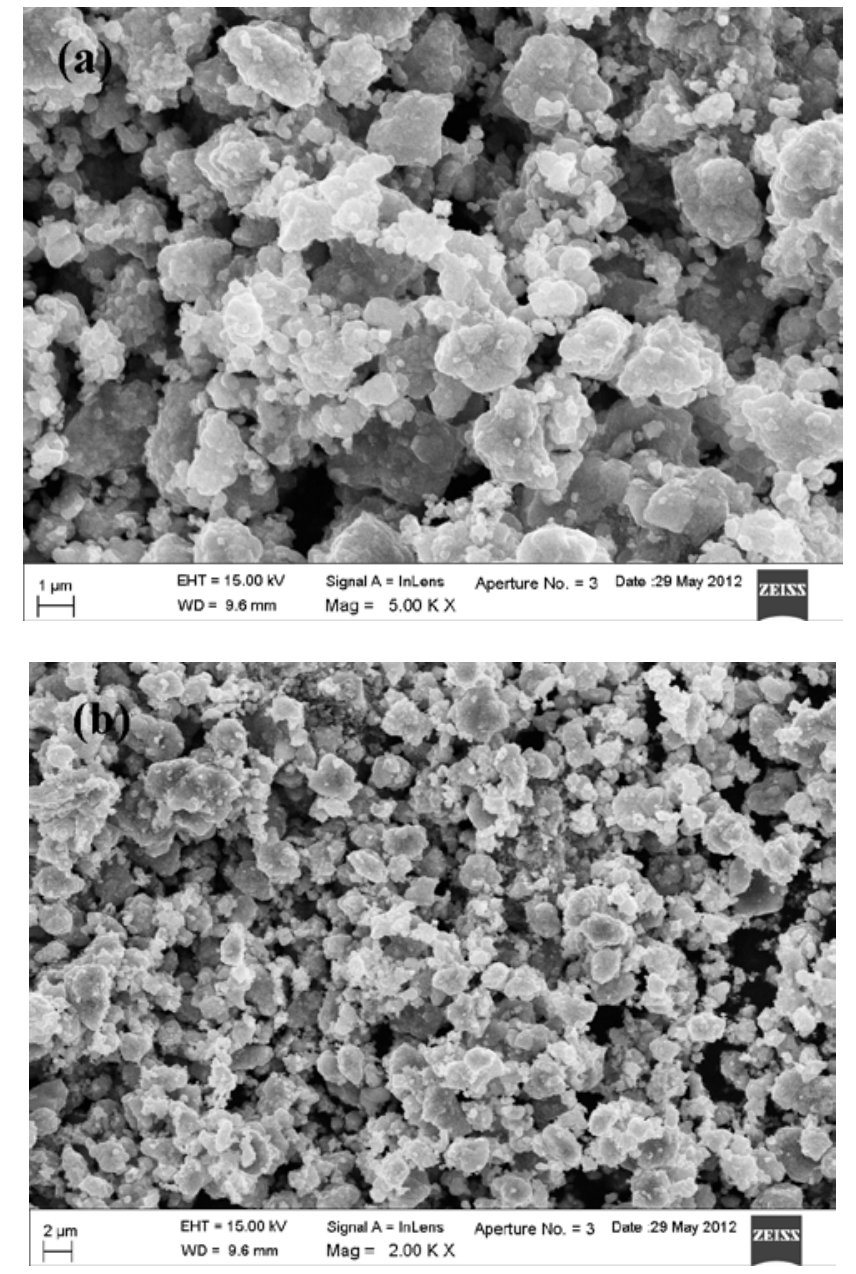

SEM images of the $\mathrm{C}-\mathrm{LiFePO}_{4}$ particles assemblies

Figure 2(a,b). SEM images

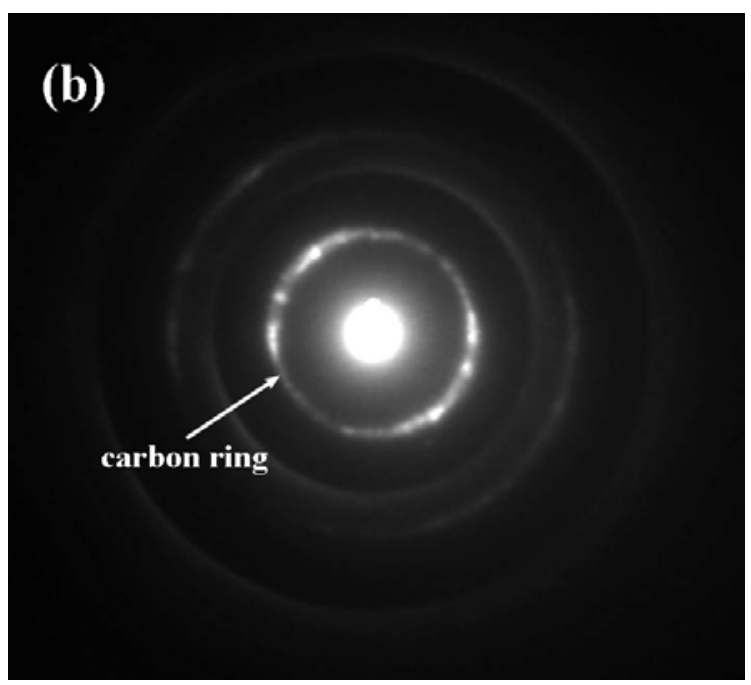



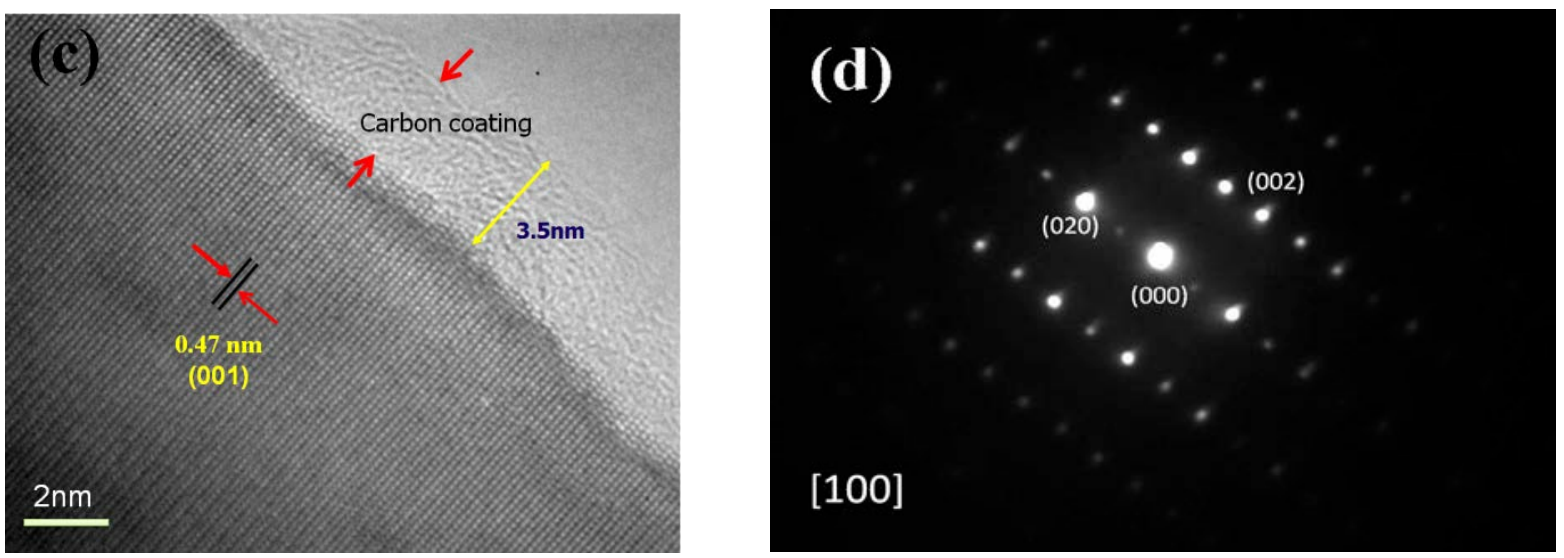

TEM and HRTEM images and SAED patterns of the $\mathrm{C}-\mathrm{LiFePO}_{4}$ particles

Figure 3(a,b,c,d). TEM and HRTEM images and SAED pattem

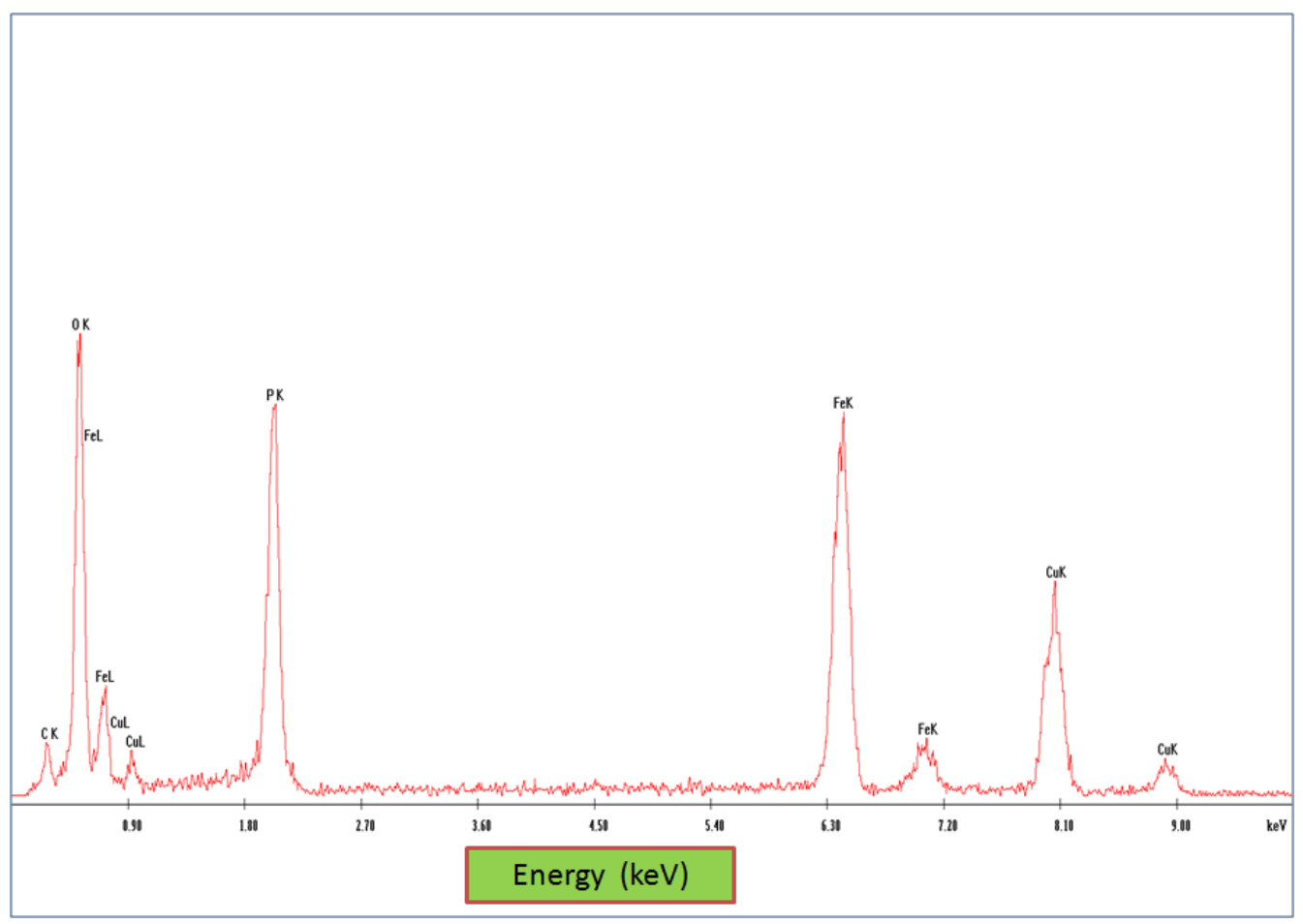

XEDS spectrum of the C-LiFePO 4 particles

Figure 4. The XEDS spectrum

From the above analysis, it convincingly shows that the as-prepared $\mathrm{C}$ - $\mathrm{LiFePO}_{4}$ particle assemblies possessed unique core-shell structure and carbon interconnection networks. This is ideal for producing the cathode with enhanced electric conductivity and excellent rate capabilities. As mentioned previously that the nano-sized $\mathrm{C}-\mathrm{LiFe} \mathrm{PO}_{4}$ particles reduce the solid-state diffusion path[13-18], which further expedite the electron and ion transport during charge-discharging processing as the cathode. These improved characteristics meet all the prerequisites for generating an excellent rate capability and a high volu metric discharge capacity in the development of the higher energy density lithium ion batteries in terms of stability, safety and excellent electrochemical properties[21-23].

The typical XPS spectrum survey profile and the core-scan spectrum of Fe $2 p$ are acquired and shown in the Fig.5a and Fig.5b, respectively. The main binding energy (BEs) of $\mathrm{Fe}_{2} \mathrm{p}_{3 / 2}, \mathrm{O} 1 \mathrm{~s}$, and C1s peaks are determined to be $710 \mathrm{eV}, 531 \mathrm{eV}$, and $285 \mathrm{eV}$, respectively, the appearance of the $\mathrm{Ti}$ and $\mathrm{N}$ peaks was from the sample support. It is also clearly seen from the Fig.5b that the Fe 2p spectrum split into $2 p_{1 / 2}$ and $2 p_{3 / 2}$ due to the spin-orbit coupling. Each part consists of a main peak and a corresponding satellite peak at BEs of $710.9 \mathrm{eV}$ and $724.4 \mathrm{eV}$ for Fe $2 \mathrm{p}_{3 / 2}$ and Fe $2 \mathrm{p}_{1 / 2}$, respectively. In fact, the appearance of satellite peaks or shoulder peaks is a characteristic feature of transition metal ions with partially filled d-orbits[24, 26], which indicated that two distinct peaks at binding energies of $710.9 \mathrm{eV}$ and $724.4 \mathrm{eV}$ were observed in the core-scan spectrum of Fe 2p. This means that the chemical oxidation state of $\mathrm{Fe}$ is +2 . 
Indeed, the two peaks could be ascribed to $\mathrm{Fe} 2 \mathrm{p}_{3 / 2}$ and $\mathrm{Fe}$ $2 \mathrm{p}_{1 / 2}$, which is characteristic of the valence of $\mathrm{Fe}^{2+}$ state in the olivine-type $\mathrm{LiFePO}_{4}$ products [25-29].

The binding energy of $\mathrm{C} 1 \mathrm{~s}$ spectrum in $285 \mathrm{eV}$ shown at Fig.5a is clearly assigned amorphous carbon with $\mathrm{sp}^{2} \mathrm{C}-\mathrm{C}$ bonds $(284.7 \mathrm{eV}$ [25]. Meanwhile, the O1s peak in the binding energy of $531 \mathrm{eV}$ represents the $\mathrm{PO}_{4}{ }^{3-}$ group oxide ions in $\mathrm{LiFePO}_{4}$. It is believed that the $\mathrm{O} 1 \mathrm{~s}$ spectra and $\mathrm{P} 2 \mathrm{p}$ spectra exhibit features at 531.6 and $133.5 \mathrm{eV}$ due to the phosphate structure[25-29]. As a result, the XPS analysis further confirms the co-existence of the olivine phase and amorphous carbon in the as-prepared $\mathrm{C}-\mathrm{LiFe} \mathrm{PO}_{4}$ cathode samples, which is in good agreement with the above both XRD and HR-TEM analysis.

Galvanostatic discharge-charge testing was electrochemically performed and with the data showed in Fig.6. It is very clear that as-prepared $\mathrm{C}-\mathrm{LiFePO}_{4}$ particles delivered and achieved an initial discharge capacity of nearly $160 \mathrm{mAh} / \mathrm{g}$ at a $0.2 \mathrm{C}$ rate as the cathode in a Li-ion cell. The peaks of capacity profiles are rather symmetric, indicating good cycle reversibility. Moreover, it also showed an excellent capacity retention ratio of $97 \%$ after the 50th charg ing/discharging cycles, which also was indicating high rate power performance as well. Obviously, such a full 3-4 $\mathrm{nm}$ carbon coating layer (i.e. carbon interconnection networks) can effectively improve particles surface electronic conductivity during discharge-charge processing. In particular, it has been believed from many reports that, the crucial role played by the surface carbon coating on the $\mathrm{LiFe} \mathrm{PO}_{4}$ particles has been responsible for the improved electrochemical performance due to the increasing of both electron and ionic transport of the $\mathrm{LiFePO}_{4}$ cathode composite particles[26-34].
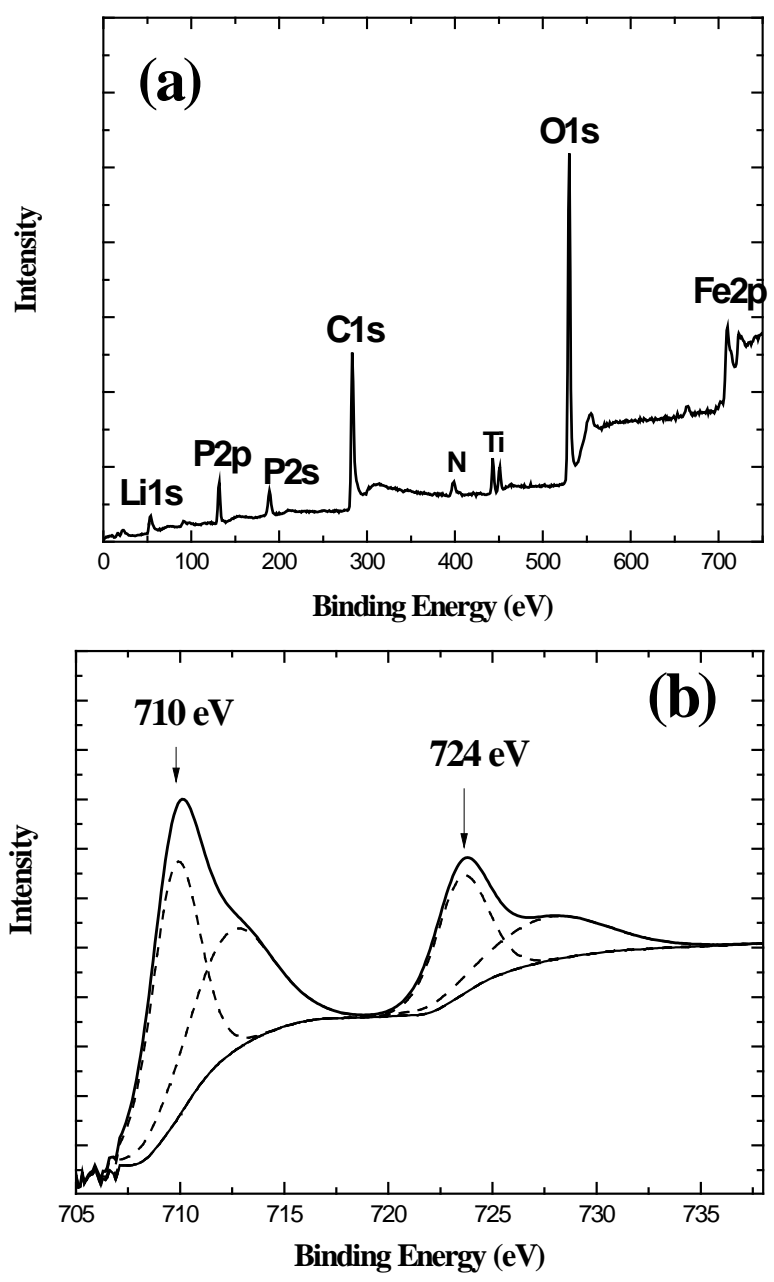

Thetypical XPS spectrum and (b) the core-XPS spectra of Fe 2p of the $\mathrm{C}-\mathrm{LiFePO}_{4}$ particles

Figure 5. (a) The typical XPS survey spectrum and (b) the core-scan spectra of Fe 2p

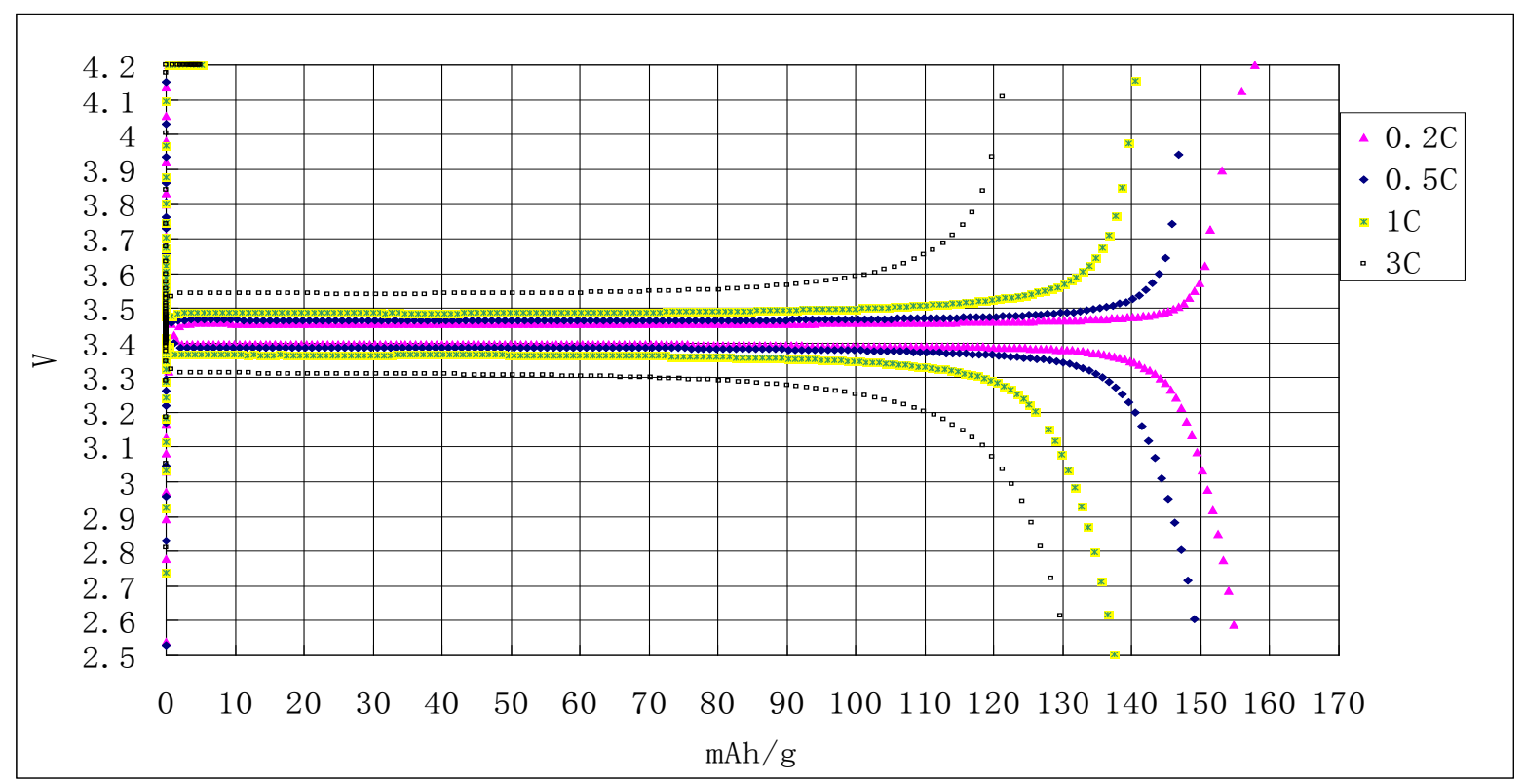

The discharge and charge profiles of $\mathrm{C}-\mathrm{LiFePO}_{4}$ nanoparticles at different current rates

Figure 6. The discharge and charge profiles 


\section{Conclusions}

1), Carbon coated $\mathrm{LiFePO}_{4}\left(\mathrm{C}-\mathrm{LiFePO}_{4}\right)$ powders products with the olivine-type structure has been successfully synthesized at commercial scale. XRD, SEM, SAED, HR-TEM image, and XPS analyses clearly provide a comprehensive view of the structure-correlated performance of the $\mathrm{C}-\mathrm{LiFePO}_{4}$ products. It demonstrates that each $\mathrm{LiFePO}_{4}$ particle has a sp2 amorphous carbon-coating shell and a phospho-olivine type crystal core.

2), The unique olivine-type $\mathrm{C}-\mathrm{LiFePO}_{4}$, combined with its full coating of conductive carbon, effectively enhances its electrochemical performance due to the presence of the carbon coating networks for both electronic and ionic transport increasing during the electrochemical testing.

3), The present mass production procedure is very valuable to optimize the process for producing carbon coated $\mathrm{LiFePO}_{4}$ cathode materials, this method is likely to be easy to scale up for industrial production.

\section{ACKNOWLEDGMENTS}

This works are financially support from the President's Award of University of Waterloo and Postgraduate Scholarship of the Natural Sciences and Engineering Research Council of Canada (NSERC).

Thanks to Jiangsu Fangzhou New Energy Company, China for offering me the collaborations for the samples preparations. Thanks also give to Prof. Jinbo Yang and Mr. Xuegang Chen for their kind XRD analysis and SEM measurements at School of Physics, Beijing University, China.

\section{REFERENCES}

[1] A. K. Padhi, K. S. Nanjundaswamy, J. B. Goodenough, "Phospho - olivines as Positive - Electrode Materials for Rechargeable Lithium Batteries”, J. Electrochem. Soc., Vol. 144, no. 4, pp.1188-1194, 1997

[2] C. M. Julien, A. Mauger, A. Ait-Salah, M. Massot, F. Gendron, K. Zaghib, "Nanoscopic scale studies of LiFePO4 as cathode material in lithium-ion batteries for HEV application”, Ionics, Vol.13, pp.395-411, 2007

[3] L. X. Yuan, Z. H.Wang, W.X. Zhang, X. L. Hu, J. T. Chen, Y.H. Huang, J. B. Goodenough, "Development and challenges of $\mathrm{LiFePO} 4$ cathode material for lithium-ion Batteries”, Energy Environ. Sci., Vol.4, pp.269-284, 2011

[4] C. A. J. Fisher, V. M. Hart Prieto, M. S. Islam, "Lithium Battery Materials LiMPO4 (M = Mn, Fe, Co, and Ni): Insights into Defect Association, Transp ort Mechanisms, and Doping Behavior”, Chem. Mater., Vol. 20, no. 18, pp.5907-5915, 2008

[5] S.-Y. Chung, J.T. Bloking Y.-M. Chiang, "Electronically conductive phospho-olivines as lithium storage electrodes", Nature Materials, Vol. 1, pp.123 - 128, 2002
[6] Y. Wang, P. He, H. S. Zhou, “Olivine LiFePO4: development and future”, Vol.4, pp.805-817, 2011

[7] H. Huang, S. C. Yi, L. F. Nazar, "Approaching Theoretical Capacity of LiFePO4 at Room Temperature at High Rates”, Electrochemical Solid State Lett., Vol. 4, no. 10, pp.A170 A172, 2001

[8] C. Sun, S. Rajasekhara, J. B. Goodenough. F. Zhou, "Monodisperse Porous LiFePO4 Microspheres for a High Power Li-Ion Battery Cathode”, J. Am. Chem. Soc., Vol. 133, no.7, pp 2132-2135, 2011

[9] S. Y. Chung, Y. M. Kim, S. Y. Choi, "Direct Physical Imaging and Chemical Probing of $\mathrm{LiFePO}_{4}$ for Lithium-Ion Batteries”, Adv. Fundional Mater., Vol. 20, no. 24, pp.4219-4232, 2010

[10] B. F. Wang, Y. L. Qiu, L. Yang, “Structural and electrochemical characterization of LiFePO4 synthesized by an HEDP-based soft-chemistry route”, Electrochem. Commun., Vol.8, no.11, pp.1801-1805, 2006

[11] G. T. K. Fey, T. L. Lu, "Morphological characterization of LiFePO4/C composite cathode materials synthesized via a carboxylic acid route”, J. Power Sources, Vol.178, no.2, pp.807-814, 2008

[12] K. T. Lee, J. Cho, "Roles of nanosize in lithium reactive nanomaterials for lithium ion batteries”, Nano Today, Vol. 6, no.1, pp. 28-41, 2011

[13] A. Yamada, S. C. Chung, K. Hinokuma, “Optimized LiFePO4 for Lithium Battery Cathodes”, J. Electrochem. Soc. Vol.148, no.3, pp. A224-A229, 2001

[14] M. Piana, B.Cushing, J. B. Goodenough, N. Penazzi, “A new promising sol-gel synthesis of phospho-olivines as environmentally friendly cathode materials for Li-ion cells", Solid State Ionics, Vol. 175, no.1-4, pp. 233-237, 2004

[15] G. Meligrana, C. Gerbaldi, A. Tuel, S. Bodoardo, N. Penazzi, "Hydrothermal synthesis of high surface LiFePO4 powders as cathode for Li-ion cells”, J. Power Sources, Vol. 160, no.1, pp. 516-522, 2006

[16] D. Choi, P.N. Kumta, "Surfactant based sol-gel approach to nanostructured $\mathrm{LiFePO} 4$ for high rate $\mathrm{Li}$-ion batteries", J. Power Sources, Vol.163, no.2, pp.1064-1069, 2007

[17] S. B. Lee, S. H. Cho, S. J. Cho, G. J. Park, S. H. Park, Y. S. Lee, "Synthesis of LiFePO4 material with improved cycling performance under harsh conditions”, Electrochemistry Commun., Vol.10, no.9, pp.1219-1221, 2008

[18] J. J. Wang, X. L. Sun, "Understanding and recent development of carbon co ating on $\mathrm{LiFePO} 4$ cathode materials for lithium-ion batteries”, Energy Environ. Sci., Vol.5, pp.5163-5185, 2012

[19] Y.G. Wang, Y.R. Wang, E. Hosono, K.X. Wang, H. S. Zhou, "The Design of a LiFePO4/Carbon Nanocomposite With a Core-Shell Structure and Its Synthesis by an In Situ Polymerization Restriction Method", Angewandte Chemie, International Edition, Vol.47, no.39, pp.7461-7465, 2008

[20] O. Toprakci, H. A. K. Toprakci, L.W. Ji, X.W. Zhang, "Fabrication and Electrochemical Characteristics of LiFePO4 Powders for Lithium-Ion Batteries" KONA Powder and Particle Journal, Vol.28, pp. 50-73, 2010 
[21] M. M. Doeff, J. D. Wilcox, R. Kostecki, G. Lau, "Optimization of carbon coatings on LiFePO4", J. Power Sources, Vol. 163, no.1, pp.180-184, 2006

[22] H. T. Kuo, T. S. Chan, N. C. Bagkar, R. S. Liu, C. H. Shen, D. S. Shy, X. K. Xing, J.F. Lee, "Effect of LiI Amount to Enhance the Electrochemical Performance of Carbon-Coated LiFePO4” Electrochemical Solid State Lett., Vol.12, no.6, pp. A111-A114, 2009

[23] S. W. Oh, S.T. Myung, H. J. Bang, C. S. Yoon, K. Amine, Y. K. Sun, "Nanoporous Structured LiFePO4 with Spherical Microscale Particles Having High Volumetric Capacity for Lithium Batteries”, Electrochemical Solid State Lett., Vol.12, no.9, pp. A181-A185, 2009

[24] N. N. Sinha, C. Shivakumara, N. Munichandraiah, "High Rate Capability of a Dual-Porosity LiFePO4/C Composite”, ACS Applied Materials \& Interfaces, Vol.2, No.7, pp.2031-2038, 2010

[25] F. Yu, J. J. Zhang, Y. F. Yang, G. Z. Song, “Up-scalable synthesis, structure and charge storage properties of porous microspheres of $\mathrm{LiFePO}_{4} @ \mathrm{C}$ nanocomposites”, J. Mater. Chem., Vol. 19, pp.9121-9125, 2009

[26] Y. H. Rho, L. F. Nazar, L. Perry, D. Ryan, "Surface Chemistry of LiFePO4 Studied by Mössbauer and X-Ray Photoelectron Spectroscopy and Its Effect on Electrochemical Properties", J. Electrochemical Society, Vol.154 no.4, pp. A283-A289, 2007

[27] L. Castro, R. Dedryvere, M. El Khalifi, P. E. Lippens , J. Breger, C. Tessier, D. Gonbeau, “The Spin-Polarized Electronic Structure of LiFePO4 and FePO4 Evidenced by in-Lab XPS”, J. Phys. Chem. C, Vol.114, no.41, pp.17995-18000, 2010
[28] H. Yang, X. L. Wu, M. H. Cao, Y.G. Guo, "Solvothermal Synthesis of LiFePO4 Hierarchically Dumbbell-Like Microstructures by Nanoplate Self-Assembly and Their Application as a Cathode Material in Lithium-Ion Batteries”, J. Phys. Chem. C, Vol.113, no.8, pp.3345-3351,2009

[29] K. Zaghib, A. Mauger, F. Gendron, C.M. Julien, "Surface Effects on the Physical and Electrochemical Properties of Thin LiFePO4 Particles”, Chem. Mater., Vol.20, no.2, pp. 462-469, 2008

[30] J. Ma, B. H. Li, H. D. Du, C.J. Xu, F.Y. Kang, "Inorganic-based sol-gel synthesis of nano-structured LiFePO4/C composite materials for lithium ion batteries”, J. Solid State Electrochemistry , Vol. 16, no. 4, pp.1353-1362, 2012

[31] C. Su, X. D. Bu, L.H. Xu, J. L. Liu, C. Zhang, “A novel LiFePO4/graphene/carbon composite as a performance improved cathode material for lithium-ion batteries”, Vol. 64, pp.190-195, 2012

[32] P. V. Braun, J. Cho, J. H. Pikul, W. P. King, H.G. Zhang, "High power rechargeable batteries", Current Opinion in Solid State and Materials Science, Vol.16 pp.186-198, 2012

[33] T. F. Yi, X.Y. Li, H. P. Liu, J. Shu, Y. R. Zhu, R. S. Zhu, "Recent developments in the doping and surface modification of $\mathrm{LiFePO} 4$ as cathode material for power lithium ion battery”, Ionics, Vol. 18, No. 6, pp. 529-539, 2012

[34] W. L. Wang, E. M. Jin, H. B. Gu, "Electrochemical Performance of Lithium Iron Phosphate by Adding Graphite Nanofiber for Lithium Ion Batteries", Transactions on Electrical and Electronic Materials, Vol.13, no. 3, pp.121-124, 2012 